\title{
Causes of failure to eradicate avian influenza in Egypt
}

Aim

In this mini-review we have presented some causes of failure to eradicate avian influenza virus in Egypt since 2006.

\section{Introduction}

HPAI is a disease of global concern because of the threat posed to food security in regions that are dependent on poultry as a main source of protein and livelihood. An additional concern is that the H5N1 virus may mutate and cause a human influenza pandemic in which millions of human lives would be threatened. ${ }^{1-4}$ Egypt experienced the disease since the first introduction of highly pathogenic Avian Influenza HPAI H5N1 in 2006. The virus widely extended in very short time and infected commercial production sectors and backyards. ${ }^{5,6}$ Failure to eradicate the virus immediately after its introduction results in establishment of an endemic state. Continued virus replication in endemic areas, and the spread from infected birds to other birds and other species in infected zones increase the risk of generating potentially pandemic AIV.

\section{Materials and methods}

AIV is influenza a virus (IAV) of Orthomyxoviridae. It has a segmented negative-sense single-stranded RNA genome. The translation products of segments 1-3 assemble into the viral transcriptase complex. ${ }^{7}$ The rapid evolutionary pattern of AIV is a result of its high rate of transcriptase errors, recombination, and reassortment. ${ }^{7,8}$ This rapid mutation is sometimes associated with adaptation to multiple host species (including humans, animals, and birds). ${ }^{7}$ It can also lead to change in virulence characteristics. The existence of susceptible wild animal and bird species adds further layers of complexity to AIV epidemiology. ${ }^{9}$ The emergence of the mutated Egyptian H5N1 mutations was observed early in 2007, ${ }^{10}$ despite the implementation of the massive vaccination. Protection from the appearance / reactivation of AIV mutations in endemic areas is partially hampered by one or more of the following factors:
i. The time required to update virus seeds
ii. Vaccine production capacity
iii. Time to import vaccines from international suppliers
iv. Use of "leaking vaccines" and ${ }^{10}$
v. Multiple, often antigenic. ${ }^{7}$

The use of leaks and multiple vaccines allows multiple antigens to replicate the virus and subsequent mutations in partially protected herds. This situation can be exacerbated by inadequate and / or unequal application of vaccines in endemic areas, poor herd conditions (e.g. poor quality of fodder, housing, management, health status, etc.). ${ }^{11}$ On the other hand, a review of the way in which so many commercial vaccines are used in endemic areas may provide an opportunity to reduce the impact of the diversity of viruses, particularly in emergencies. ${ }^{12}$ Updated vaccine seed is the optimal approach to

\author{
Volume I Issue 4 - 2017
}

\author{
Hussein A Kaoud \\ Department of Veterinary Hygiene, Cairo University, Egypt
}

Correspondence: Hussein A Kaoud, Department of Veterinary Hygiene, Cairo University, Egypt, Email ka-oud@link.net

Received: September 26, 2017 | Published: October 26, 2017

provide protection against emerging AIV strains. However, the success of vaccine application is often limited through logistics to produce vaccines and deliver them to affected areas. The existing knowledge related to molecular biology and AIV evolution has been used to propose a rapid and feasible intervention tool in the face of emerging viruses.

\section{Conclusion}

Incorrect application of vaccine-based control strategies contributes to AIV diversity and results in complication of the epidemiological situation. The Egyptian situation is a clear example of this problem. Although vaccination against AIV H5N1 was adopted in Egypt since 2006, severe avian influenza (AI) associated with HP AIV H5N1 continue to be reported in vaccinated flocks. Phylogeneticallydivergent $\mathrm{H} 5 \mathrm{~N} 1$ viruses, which are only partly antigenically crossreactive, co-circulate in Egypt. The Egyptian situation poses a threat to the rest of the world.

\section{Acknowledgements}

None.

\section{Conflict of interest}

The author declares that there is no conflict of interest.

\section{References}

1. Li K, Guan Y, Wang J, et al. Genesis of a highly pathogenic and potentially pandemic H5N1 influenza virus in eastern Asia. Nature. 2004;430:209-213.

2. Zambon M. Active and passive immunization against respiratory syncytial virus. Reviews in Medical Virology. 1999;9(4):227-236.

3. Barclay WS, Zambon M. Pandemic risks from bird flu. $B M J$. 2004;328(7437):238-239.

4. WHO (World Health Organization), WHO Global Influenza Preparedness Plan. The role of $\mathrm{WHO}$ and recommendations for national measures before and during pandemics, Switzerland, pp. 1-53.

5. Kaoud H. HPAI epidemic in Egypt: evaluation, risk factors and dynamic of spreading. International Journal of Poultry Science. 2007;6(12):983-988

6. Aly MM, Arafa AA, Hassan MK. Epidemiological findings of outbreaks of disease caused by highly pathogenic $\mathrm{H} 5 \mathrm{~N} 1$ avian influenza virus in poultry in Egypt during 2006. Avian Dis. 2007;52(2):269-277. 
7. Lamb RA, Krug RM. Orthomyxoviridae: The viruses and their replication. In: Knipe DM, Howley PM, editors. Fields Virology. 4th edn. Lippincott: Philadelphia, USA; 2001. p. 1487-1531.

8. Boltz DA, Douangngeun B, Phommachanh P, et al. Emergence of $\mathrm{H} 5 \mathrm{~N} 1$ avian influenza viruses with reduced sensitivity to neuraminidase inhibitors and novel reassortants in Lao People's Democratic Republic. $J$ Gen Virol. 2010;91(pt 4):949-959.

9. Abdelwhab EM, Hassan MK, Abdel Moneim AS, et al. Introduction and enzootic of $\mathrm{A} / \mathrm{H} 5 \mathrm{~N} 1$ in Egypt: Virus evolution, pathogenicity and vaccine efficacy ten years on. Infect Genet Evol. 2016;40:80-90.
10. Beato MS, Mancin M, Yang J, et al. Antigenic characterization of recent $\mathrm{H} 5 \mathrm{~N} 1$ highly pathogenic avian influenza viruses circulating in Egyptian poultry. Virology. 2013;435(2):350-356.

11. Watanabe Y, Ibrahim MS, Ellakany HF, et al. Antigenic analysis of highly pathogenic avian influenza virus $\mathrm{H} 5 \mathrm{~N} 1$ sub lineages co-circulating in Egypt. J Gen Virol. 2012;93(10):2215-2226.

12. Read AF, Baigent SJ, Powers C, et al. Imperfect vaccination can enhance the transmission of highly virulent pathogens. PLoS Biol. 2015;13(7):e1002198. 